\title{
Visual Representations of Digital Connectivity in Everyday Life
}

\author{
Wendy Martin ${ }^{1(\varpi)}$ and Katy Pilcher ${ }^{2}$ \\ ${ }^{1}$ College of Health and Life Sciences, Brunel University London, \\ Uxbridge, Middlesex UB8 3PH, UK \\ wendy.martin@brunel.ac.uk.at \\ 2 School of Languages and Social Sciences, Aston University, \\ Birmingham, B4 7ET, UK \\ k.pilcher@aston.ac.uk
}

\begin{abstract}
This paper draws on data from the empirical study Photographing Everyday Life: Ageing, Lived Experiences, Time and Space funded by the ESRC, UK. The focus of the project was to explore the significance of the ordinary and day-to-day and focus on the everyday meanings, lived experiences, practical activities and social contexts in which people in mid to later life live their daily lives. The research involved a diverse sample of 62 women and men aged 50 years and over who took photographs of their different daily routines to create a weekly visual diary. This diary was then explored through in-depth photo-elicitation interviews to make visible the rhythms, patterns and meanings that underlie habitual and routinized everyday worlds. The data was analysed using the software Atlas Ti. The analysis highlighted: (1) the increasing importance of digital connectivity and the ways in which people in mid to later life actively engage (and resist) technologies of communication in their daily lives; and (2) the significance of embodied co-presence and the immediacy of shared space and/or time. Exploring the routines, meanings, and patterns that underpin everyday life has therefore enabled us to make visible how people build, maintain and experience their social and virtual connections, and the ways in which digital devices and information technologies are being incorporated into (and resisted) within daily life.
\end{abstract}

Keywords: Ageing digital $\cdot$ Everyday life $\cdot$ Social connections $\cdot$ Space and time

\section{Introduction}

The $21^{\text {st }}$ century has been characterized by a proliferation of digital devices, information technologies and mediated systems of communication within global and networked societies. Digital technologies permeate everyday life more and more [1] and have become interwoven with our identities, narratives, social relationships, social networks, lifestyles and societies. As people grow older their everyday lives will therefore become increasingly mediated by the proliferation of digital technologies and have a profound influence on the social worlds of people in mid to later life [2, 3]. At the same time there have been concerns that there is a digital divide in which older people are excluded from 
participation [4-8] and the extent to which the digital is mainly focused on younger people. From a review of the literature on Information and Communication Technologies (ICT) older people are moreover often framed as 'passive' and 'dependent' receivers of new technologies and issues of surveillance and control predominate amongst the oldest old [3, p. 442], see also [9]. Whilst the digital divide may now be narrowing, except amongst the oldest old $[3,10]$, there is limited research into the ways in which people in mid to life incorporate digital technologies and communications into their daily lives and their own meanings and experiences of the digital as they grow older.

This paper draws on data from the empirical study Photographing Everyday Life: Ageing, Lived Experiences, Time and Space funded by the Economic and Social Research Council (ESRC) in the United Kingdom. The focus of the project was to explore the significance of the ordinary and day-to-day and focus on the everyday meanings, lived experiences, practical activities, and social contexts in which people in mid to later life live their daily lives. In particular, the project focused upon the very ordinariness and mundanity of daily living; and the day-to-day practical activities and personal meanings embedded within the personal, domestic and working lives of the participants. In order to make these everyday lives visible, the project involved visual methods (photographic diaries) and in-depth interviews (photo elicitation) with people aged 50 years and over who had different types of daily routines. In this context, the research aimed to be much closer to lived experiences and how people give meaning and engage with their own everyday lives in their own terms. As Gubrium and Holstein [11] argue a focus on daily life can generate important insights into 'how people themselves interpret and discern what it's like to grow older and be old in today's world' (2000, p. 3). Exploring the routines and patterns that underpin the everyday lives of people growing older have moreover enabled us to make visible how people build, maintain and experience their social and virtual connections.

\section{The Research Project}

The research involved a diverse sample of participants who took photographs of their different daily routines to create a weekly visual diary. Within the study there were 42 women and 20 men who participated aged between 52 and 81 years. There was a variety of routines amongst the sample, which included some participants who had retired, others who were in full and part time paid employment, some working as volunteers, and a number of the participants who had a combination of these roles. We recruited participants in the South of England, through a range of organizations and social groups aimed at people aged 50 years and over, as well as a variety of workplaces, sports and leisure centres, and social venues. In total there were 4471 visual images created by participants across the project, and interviews lasted for an average of about $46 \mathrm{~min}$. Ethical approval was gained from Brunel University London, College of Health and Life Sciences Ethics Committee (Reference 10/04/STF/08).

The first stage of the study involved a researcher meeting with a participant to explain more about the project, hand over a digital camera, and to give appropriate support and 
guidance on how to use the camera. Participants then took photographs that depicted important aspects of their daily lives for one week. This was a participatory approach in the sense that participants are in control of the cameras and they can decide what to photograph (or not). In this sense the photographs act as a 'visual diary' of a participant's life and their daily routines across one week. The second stage of the research involved a researcher meeting the participants (usually in their own home, office, or a private area), to engage in a photo-elicitation interview. The photographs were uploaded onto a laptop computer at the start of each interview and were used as a resource to facilitate conversations. The photographs provided a reference point to focus and 'prompt' discussion during in-depth interviews in which we explored meanings, activities, roles, relationships, space, time, and participants' reasons for taking the photographs and the context of their visual diary.

The data was analyzed using Atlas Ti software as it enabled the incorporation and comparison of visual and textual data. We coded and thematically analyzed both the photographs and textual data to explore aspects of daily lives, time and space. For a more in-depth exploration of the methodological and ethical issues encountered within the research project see Pilcher et al. (2016) [12]. In this paper we focus on one dimension of an emergent theme - social connectivity and relationships - that highlighted an increasing presence of digital technologies and the active engagement of the participants with new technologies of communication within their daily lives.

\section{Connectivity, the Digital and Everyday Life}

It is argued that contemporary and global societies are characterized by changes in meanings and experiences of time and space, in which there has been a move from predominately face to face relationships in which time and space are inextricably linked, to an increasing separation of time and space resulting in more disembedded and distanciated social relationships [13, 14], a process that has further deepened in a network society in which connectivity is immediate and global $[15,16]$. Massey [17] criticizes the dualist tendency of conceptualizing space and time as bounded and separate, and instead states that space and time are intimately interconnected, and are constructed out of social relations, within a context in which social relations are dynamic and changing. A focus on social relations further highlights the ways in which a proliferation of digital technologies can influence the ways we create and experience social connectivity in our daily lives [18]. It has been through a focus on daily life, and an exploration of the ways in which age and ageing are culturally mediated and subjectively experienced [19, 20], that has provided important insights into positive and negative dimensions of social connectivity as people grow older in a digital world.

Data from the Photographing Everyday Life research project illustrated the importance of connectivity, that is connections with family, partners, friends and the locality, as well as wider inter/national communities, amongst the participants. These social connections were interspersed throughout the daily lives of the participants. Social connections were maintained or created virtually (for example, social networking, emails, video calls) and in shared space and/or time (for example, the telephone, living 
or working together, visits). Participants portrayed how they incorporated a diverse range of digital, computer and mobile technologies via the images from their visual diaries, for example, mobile phones, smartphones, tablets, laptops and computers:
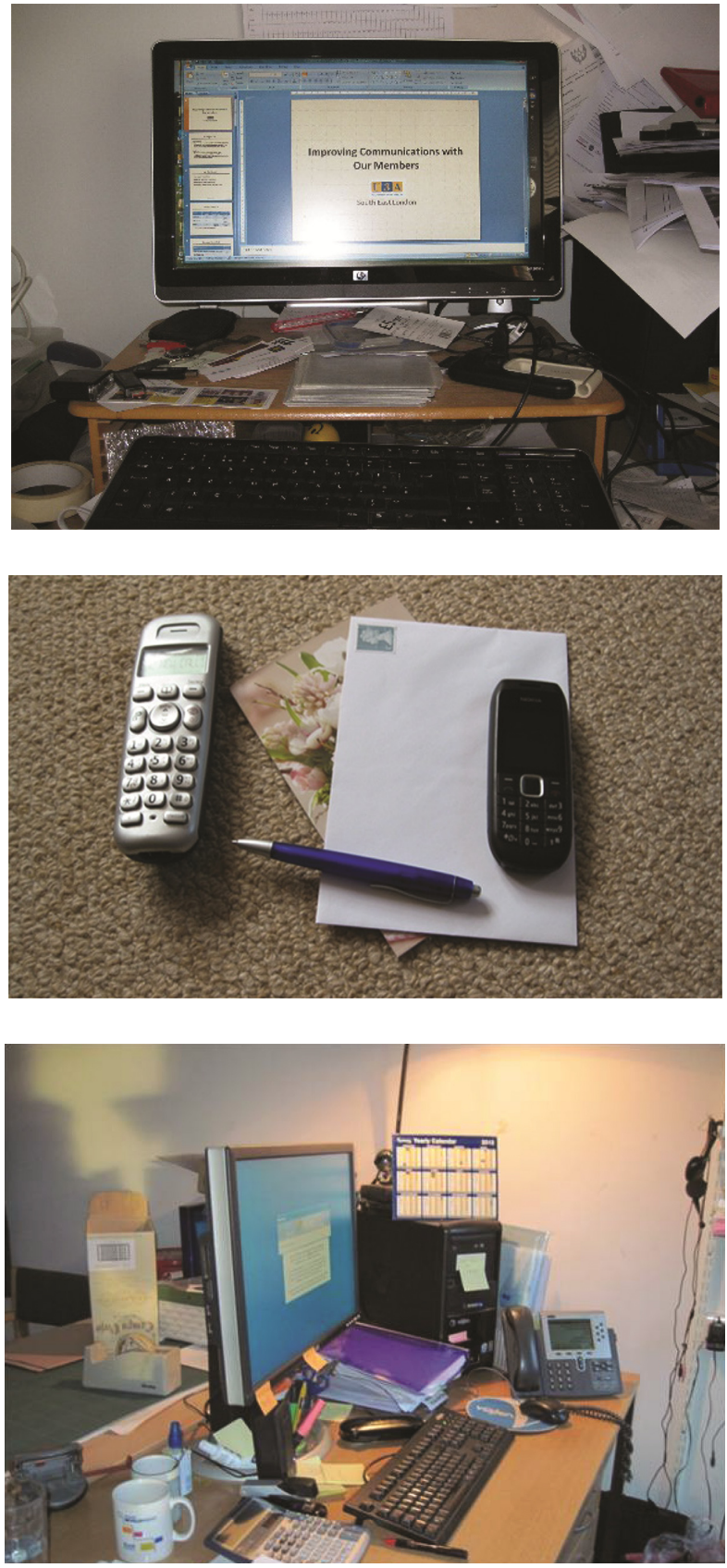


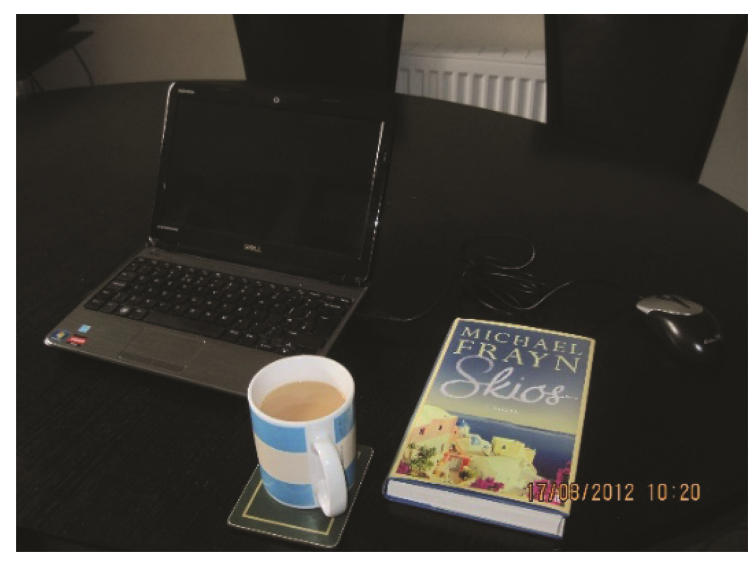

The digital and networked technologies were located in the participants' domestic spheres and their homes, including the lounge / front room, bedroom, study and kitchen; in public spaces, such as libraries, meeting rooms / halls, and at social events; in the work environment; and as mobile devices that were carried with the person.

The materiality of the digital and networked devices were evident, as objects and as screens, and can be seen to have become incorporated into the everyday infrastructure and daily rhythms and routines of most of the participants [21]. Many participants described the ways in which the use of online and digital resources, as a means to create and maintain social connections, were embedded and interspersed throughout their daily routines:

And also I realised how much the thread of the day, because I sort of observed you know, for a week before of the kind of, sort of life, it was quite a reflective thing really to see what my week was.. And I realised how much of it, also revolved round the computer, which we've set up upstairs. We have a kind of bedroom office, in terms of e-mailing and with the phone next to it, keeping in touch with people. So I suppose somewhere in the day I'd spend at least an hour on the computer, either sending or replying to e-mails or looking up e-mails and there's a great sort of teetering pile of stuff that is either to be read or dealt with. (Hannah, aged 68 years, married)

The place and location of computers and laptops were part of the social and material fabric and were noticeable within the domestic and work environments of many of the participants and often provided significance and meaning about the use of space within their everyday lives:

Yes, that's my office. I've got my printer and my computer and everything else, yes. But it's quite cool. You close the door and you know, everything goes away. (Victoria, 61 years, divorced)

The participants described that despite the prominence of digital and networked devices, there was predominately a purpose for their activities and practices when engaging with digital and online media and communications, that included enhancing social and virtual connections by communicating with family, friends and social groups, to search and find information, as part of their paid or voluntary work, and for enjoyment and pleasure, such as music, videos, games and chatrooms: 
Yes, I think a lot of time. if I am alone I might be reading or on the computer. Sometimes chatting, very, very little. Not much. But usually just looking something. If I have a new thing then, then reading a book, if I find some then I'll go and go to Wikipedia things like that. (Zuberi, aged 66 years, divorced)

The nature and role of social relationships, their living arrangements, such as living alone, and the proximity of friends and family of the participants influenced the types of media and communications, the extent and meanings of engagement and the ways participants experienced and used digital technologies. Some participants described how social media enabled them to maintain social identities and be involved in the everyday worlds of their family across the generations, as well as with friends and family who live at a distance:

And I'm back on my Facebook you see..... I am. I'm on usually at least twice a day. Just to see.... Because I have a large family. There's [er] I'm Mother Nature I suppose. I have four children, eight grandchildren and I've got six great grandchildren. So my four children and my eight grandchildren are all going on Facebook. And that's all... and a couple of friends I connect to. So all the time I can see what's going on. (Annabel, aged 65 years, lives with partner)

Different types of social media, including Facebook and online forums, and video calls, such as Skype, enabled participants to engage virtually with and participate in intergenerational connections and keep updated on the daily lives of significant relationships. This was especially important when important family members lived at a distance, such as adult children and grandchildren:

We SKYPE or phone. I mean the baby's two, but yes, he's that's not... I don't mind them being away but I think it would be nice to see them at least once a month because... And the point of SKYPE is really good. It makes such a huge difference. To be able to see who you're talking to at the same time, and, because again when we're in France, we can say to them oh the sun flowers are out, and oh look, you know, and show them the sunflowers. (Mark, 66 years, married)

The visual dimensions of and the immediacy of seeing one another on video calls was especially highlighted by some participants as a means to sustain meaningful social connections:

I use skype quite a lot to keep in touch with my family, one of my sons lives in Qatar and they don't have a phone line or postal service so we talk on skype, or I talk to my grandchildren who live in England, I can also use the video with them and see them on the screen. (Dorothy, age 73 years, widow)

And if you've got Skype you know, why do you need to be visiting all the time? You can see your grandchildren on Skype and talk to people on Skype. We talk to a lot of people on Skype. The wife talks to a lot of her friends in Hungary on Skype. So we don't go into Facebook and Twitter. We're not twittering people I'm afraid and so that's you know. (Christopher, 75 years, married)

For some participants the significance of digital and networked technologies was the potentiality of time and ability of 'being there' if and when needed. This could relate to key roles and relationships associated with care:

Yes, friends a lot, family, work, everybody really through the phone. It's kind of constantly there. I've an elderly auntie whose a bit like my Mum, and because my Mum's dead and she's got dementia, so I keep the phone pretty close to me, because she does phone me up sometimes with odd and unusual requests. So I need to keep an eye on that, you know, in case she phones... She 
phoned me up the other day to say where was she going for the weekend, and I said what do you mean, and she said well I've packed my bags but I'm not sure where I'm going. And I realised it was because we'd been talking about Christmas arrangements and she'd be going away. She'd packed her bags about four weeks too early. (Samantha, 53 years, divorced)

Or alternatively some participants would undertake other practical domestic and work activities whilst anticipating social and digital communications and connections, in particular, with family members. Naomi, for example, described how she was ironing while awaiting a potential and possible video call from her son:
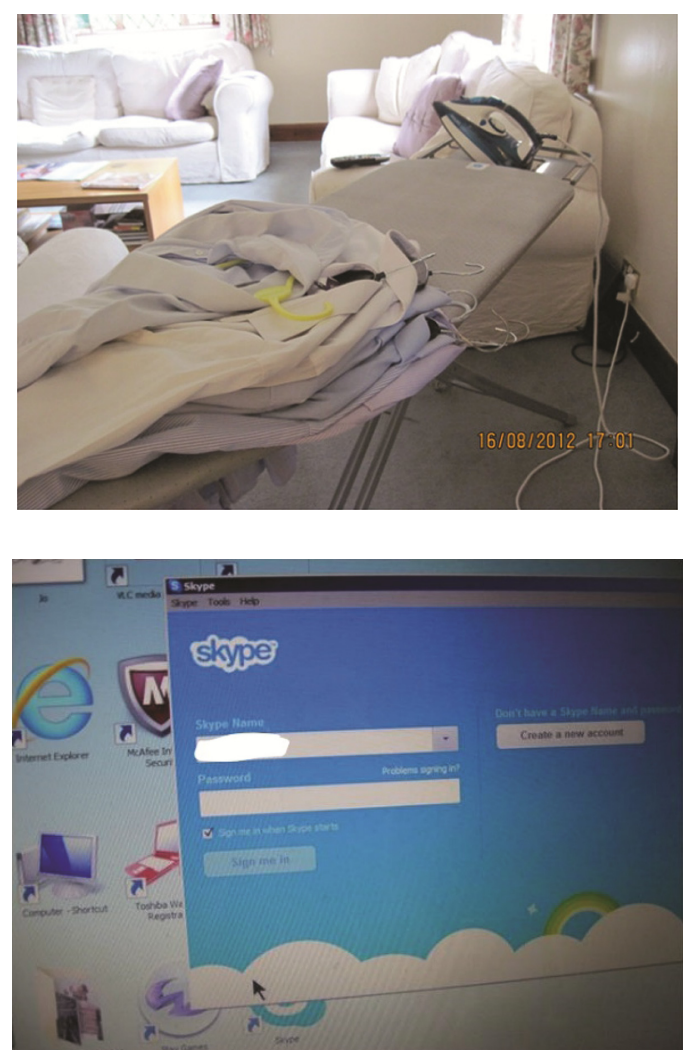

I also put on Skype, as I think I've mentioned before, some of my sons are abroad. ... And the youngest one whose in Corsica at the moment, said that he would be skyping us. So I put skype on ... but he didn't call ... But it was in the room next to where I was ironing. I had it on just in case, you know, he did say.... So that's another way that I keep in touch with them when they're away. (Naomi, aged 55 years, married)

Some participants would also portray and describe how they use multiple sources of media, digital and networked devices and communications at the same time, and / or move between different media: 

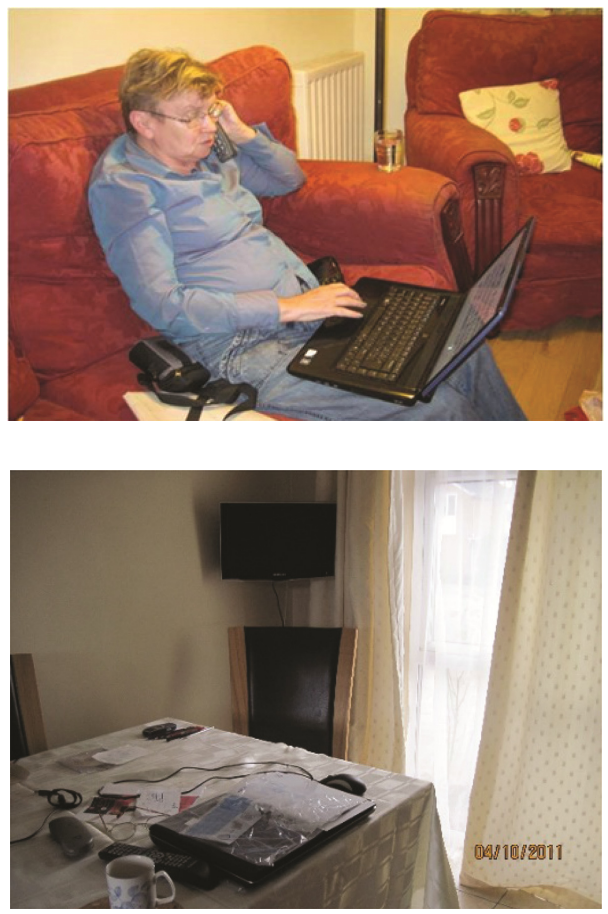

So yes, I would be watching the telly and if it was something that he was watching then I'd be checking my e-mails and stuff on my iPad. I love my iPad. (Catherine, 58 years, married)

I get my e-mails on it. I get loads of texts on it. I keep my diary on it. Got Facebook and Twitter and YouTube and things and some music on it I have some music on it. (Samantha, 53 years, divorced)

Whilst there were many positive dimensions and opportunities, there were some limitations and difficulties expressed about the amount and type of virtual connections and online activity amongst some participants. A key issue for some participants was that not all the people or social groups that a participant would want to communicate with had digital and networked devices. In this context age and generation were often identified as significant factors and dominant imageries of age and ageing were at times drawn upon:

Irene: I talk to my friends on the phone constantly, during the day, any time.

I: So more on the phone rather than e-mail?

Irene: Yes. Yes. Not all of my friends have e-mail ... and I'd sooner talk to people then e-mail them. (Irene, 68 years, divorced)

Phillip: So I actually bound it together as a report and send it out in the post.

I: Okay. 
Phillip: But normally. But not everybody's got e-mail. About $15 \%$ of our members aren't on email.... Which is still quite. But one of the problems is people use that as an excuse not to move into the electronic era.

\section{I: Okay yes.}

Phillip: We can't do that because some people can't do e-mails. Well as long as they get it some other way it doesn't matter.

I: Yes.

Phillip: You know, all of our new members, the members who are showing up now who are in their late 50s 60s who are joining expect us to be using e-mail. They expect us to have. Which we can do. We can send out the programme and the newsletter by e-mail but that's how they expect us to communicate with them. (Phillip, 68 years, married).

Other concerns that participants highlighted about using new media and networked devices were their own perceptions of not having sufficient technological skills and knowledge and /or safety concerns when online, that can include identity theft, sharing and loss of control of personal information and potential financial fraud:

I: Do you use social networking or something like that at all or is it mainly the e-mail

Jennifer: No I don't go on the, I don't like Facebook or Twitter or anything like that. I don't think they're safe (Jennifer, 68 years, married)

Moreover, whilst there were perceived to be many constructive and meaningful dimensions to digital communications and connections, many participants emphasized the continuing importance of locality and embodied co-presence, that is being in the same place at the same time as others including family, friends, work colleagues, neighbours and local social connections:

Irene: Every month we go for lunch with U3A [University of the Third Age]... Different places. The, the lunch club [um] organises and susses the places out and then we just go and enjoy the meal and good company. That's it, some more people from the lunch. That's me having lunch and a glass of wine I hasten to add, with the lunch. Because I went into Abingdon on the bus.

I: So it looks like you quite enjoy going out for meals?

Irene: I do. Yes. It's nice to have company. When you live on your own its good to have company. To eat with someone else instead of eating on your own. (Irene, 68 years, divorced)

The significance of embodied co-presence and social connectivity involved many varied and diverse activities including regular coffee mornings with neighbours, talking on the telephone, walking clubs, exercise classes, dog walking in the locality, participating in social groups, voluntary work, and sharing meals: 

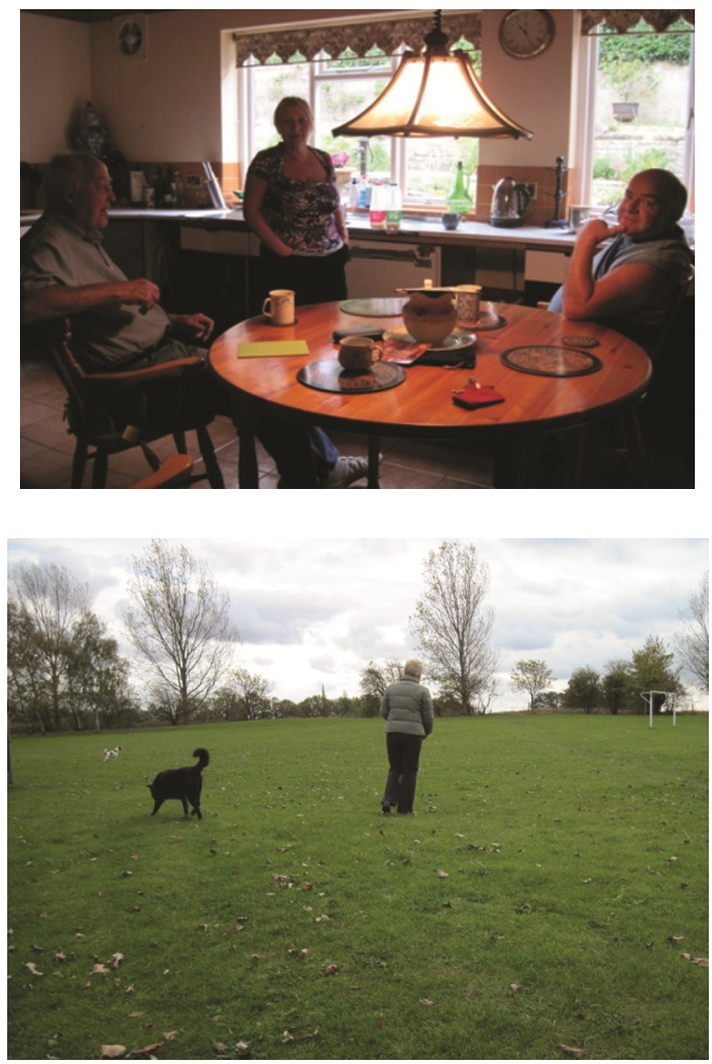

Oh this is more dogs. As I say I don't expect you to keep these, but this is just how many we meet up with. All these people every morning have got owners. So we all have a chat and it's quite a community actually. (Patricia, 70 years, widow)

\section{Concluding Comments}

Photographs from a visual diary depict 'a sequence of ... frozen moments, each of which is exceptional by the fact of being singled out' by a participant, in which the images portrayed are 'heightened' ordinary moments' of daily life [22, p. 35]. The images from the visual diaries can be seen to represent moments, rhythms, environments and practices that are meaningful within the ordinary, mundane and everyday routines of the participants. The increasing presence of digital devices and screens portrayed in the visual diaries as people grow older was therefore significant. The daily lives of people in mid to later were not only mediated, experienced and enacted in relation to digital and networked devices but digital objects and screens have increasingly become central to the everyday fabric of material and social domestic and working environments. Social connectedness was enhanced as people in mid to later life were able to create, build and maintain social relationships in the context of their everyday life. This included 
communications between different generations and with family, friends, colleagues and social groups both at a distance and in the locality; and the interconnectedness of time that was experienced and perceived as separate, simultaneous and/or immediate. The incorporation of digital and networked technologies has therefore influenced the context of social relationships and meanings and experiences of time and space. The significance of embodied co-presence, of being in the same shared space and time was prominent within the visual diaries and the meaning of being in immediate and direct connection with others as we grow older cannot therefore be under-estimated. The narratives of the participants moreover portrayed an active engagement with digital devices in which people in mid to later life made active choices about the opportunities and possibilities, as well as at times actively resisting being drawn into the increasing pace and predominance of digital and media technologies.

To conclude, we recognize the limitations in our portrayal of the visual and lived experiences of digital technologies in everyday life as social connectivity and the increasing presence of digital and networked technologies was an emergent theme and not the main focus of the research. The research has however highlighted the dynamic and changing context of social connectivity in a digital world that is experienced and understood as meaningful and significant in the daily lives of people in mid to later life which does therefore open up the possibility for future research.

Acknowledgements. This research was supported by funding from the Economic and Social Research Council / ESRC [grant number RES-061-25-0459] in the United Kingdom. We would like to thank our research participants for the generosity of their extensive time taken to participate in this research. Pseudonyms are given in this paper. Thank you also to our advisory group for their support and guidance, to Dr Veronika Williams who worked on earlier parts of the project, and to Dr Christina Silver for her invaluable technical and analytical support.

Copyright of Visual Images. Copyright for all the visual images published in this paper belongs to Dr Wendy Martin, Brunel University London, UK. Participants have provided written permission that the visual images can be published.

\section{References}

1. Lupton, D.: Digital Sociology. Routledge, Abington (2014)

2. Loos, E.F., Haddon, L., Mante-Meijer, E.A. (eds.): Generational Use of New Media. Ashgate, Farnham (2012)

3. Jones, I.R.: Connectivity, digital technologies and later life. In: Twigg, J., Martin, W. (eds.) Routledge Handbook of Cultural Gerontology. Routledge, Abingdon (2015)

4. Jaeger, B.: Trapped in the digital divide? Old people in the information society. Sci. Stud. 17, 5-22 (2004)

5. Gilleard, C., Higgs, P.: Internet use and the digital divide in the english longitudinal study of ageing. Eur. J. Ageing 5, 233-239 (2008)

6. Loos, E.F.: Senior citizens: Digital immigrants in their own country? Observatorio (OBS*) J. 6(1), 1-23 (2012)

7. Loos, E.F.: Designing for dynamic diversity: Representing various senior citizens in digital information sources. Observatorio (OBS*) J. 7(1), 21-45 (2013) 
8. Olphert, W., Damodaran, L.: Older people and digital disengagement: A fourth digital divide? Gerontology 59, 570-574 (2013)

9. Peine, A., Faulkner, A., Jaeger, B., Moors, E.: Science, technology and the 'grand challenge' of ageing - Understanding the socio-material constitution of later life. Technol. Forecast. Soc. Chang. 93, 1-9 (2015)

10. Gilleard, C., Jones, I.R., Higgs, P.: Connectivity in later life: The declining age divide in mobile cell phone ownership. Sociol. Res. Online 20(2), 3 (2014)

11. Gubrium, J., Holstein, J. (eds.): Aging and Everyday Life. Blackwell, Oxford (2000)

12. Pilcher, K., Martin, W., Williams, V.: Issues of collaboration, representation, meaning and emotions: Utilising participant-led visual diaries to capture the everyday lives of people in mid to later life. Int. J. Soc. Res. Methodol. 19(6), 677-692 (2016)

13. Giddens, A.: Time-Space distanciation and the generation of power. In: A Contemporary Critique of Historical Materialism. Power, Property and the State. MacMillan, London (1981)

14. Giddens, A.: Modernity and Self Identity. Polity Press, Cambridge (1991)

15. Castells, M.: The Rise of Network Society: Information Age: Economy, Society and Culture. Blackwell, Oxford (1996)

16. Castells, M.: Communication Power. Oxford University Pres, Oxford (2009)

17. Massey, D.: Space Place and Gender. Polity Press, Cambridge (1994)

18. Chayko, M.: Techno-social life: The internet, digital technologies and social connectedness. Sociol. Compass 8(7), 976-991 (2014)

19. Twigg, J., Martin, W.: The challenge of cultural gerontology. Gerontologist 55(3), 353-359 (2015)

20. Marshall, B., Katz, S.: How old am I? Digital culture and quantified ageing. Digit. Cult. Soc. 2(1), 145-152 (2016)

21. Horst, H.: New media technologies in everyday life. In: Horst, H., Miller, D. (eds.) Digital Anthropology. Bloomsbury Academic, London (2012)

22. Chaplin, E.: My visual diary. In: Knowles, C., Sweetman, P. (eds.) Picturing the Social Landscape. Routledge, London (2004) 